\title{
4. The political significance of data visualization: Four key perspectives
}

\author{
Torgeir Uberg Ncerland
}

\begin{abstract}
Practitioners and scholars alike assume that data visualization can have political significance - as vehicle for progressive change, manipulation, or maintaining the status quo. There are, however, a variety of ways in which we can think of data visualization as politically significant. These perspectives imply differing notions of both 'politics' and 'significance'. Drawing upon political and social theory, this chapter identifies and outlines four key perspectives: data visualization and 1) public deliberation, 2) ideology, 3) citizenship, and 4) as a political-administrative steering tool. The aim of this chapter is thus to provide a framework that helps clarify the various contexts, processes, and capacities through which data visualizations attain political significance.
\end{abstract}

Keywords: Data visualization; Politics; Democracy; Citizenship; Ideology

\section{Introduction}

Data and their visualizations are becoming increasingly important in a variety of domains of Western societies (van Dijck, 2014; Couldry \& Hepp, 2016). Kennedy, Hill, Aiello, and Allen (2016, p. 715) comment that '[...] data are becoming increasingly valued and relied upon, as they come to play an ever more important role in decision-making and knowledge about the world'. Through their encoding, circulation, and uptake in private, public as well as institutional contexts, data visualizations operate in real-world contexts where politics and power are at work. As such, they have potential significance as instruments or sites for change.

Engebretsen, M. and H. Kennedy (eds.), Data Visualization in Society. Amsterdam: Amsterdam University Press, 2020 DOI 10.5117/9789463722902_CHO4 
However, where this significance resides, and how data visualizations become politically significant, is both a matter of context and of how we define 'politics'. This chapter outlines what are argued to be the four most important perspectives through which we can think of data visualizations as politically significant. In doing so, it outlines the contexts these perspectives belong to and the notion of politics these contexts imply.

Before we can outline these perspectives, it is necessary to make some general demarcations about what we mean when we talk about political significance in the context of data visualizations. First, 'politics' may be understood in narrow terms, as the workings of political parties, processes, and institutions. Politics may also be understood in a wider sense, as the struggle for power more broadly, as this struggle takes place both in the private as well as the cultural sphere, and by symbolic as well as material means. The perspectives outlined in this chapter span from narrow to wide understandings of politics. As will be outlined, data visualizations may assume direct significance as part of the decision-making processes in political institutions. Or, as will be highlighted, data visualizations may assume less direct yet critical significance as a resource for citizenship and participation, or as part of ideological struggles.

Second, we need to clarify what we mean by significance. This chapter is concerned with the effects the circulations of data visualizations have on society. The chapter premises that for data visualizations to be politically significant, they need to be engaged with in real life contexts-be it in institutional or informal contexts. They need to be connected to processes of change, or the maintaining of the status quo.

In the following, four perspectives are presented. These perspectives do not exhaust the possible ways through which data visualizations may lead to change in the world. Rather, they synthesize what is argued to be the main variants. Moreover, there may be considerable overlap between the perspectives presented, and they are indeed interlinked. Yet, these perspectives are not reducible to each other.

\section{Data visualization and public deliberation}

Data visualization and public deliberation is a perspective capturing scenarios where data visualizations enter public discussion concerning matters that are contested or that need collective resolution. This perspective is closely affiliated with what has come to be known as a deliberative model of democracy (Habermas, 1994). This model presupposes a well-functioning public sphere, 
a space where different actors - private, institutional, political-come together to discuss matters of collective importance. Such space may be of a physical nature, as in the case of pubs or assembly halls. But when we today talk about the public sphere, we primarily mean the symbolic space facilitated by the media. It is a normative model inasmuch as it posits that deliberation - the public exchange of arguments - should be rational, and the public opinion that arises from deliberation should form the basis for legitimate political decision-making.

A deliberative model of democracy emphasizes the importance of citizen participation and the public exchange of rational arguments. Crucially, the discussion that takes place in the public sphere is, ideally, connected to actual decision-making. The public sphere should be the mediating space between private persons, civil society, and political decision-makers (Habermas, 2006). The core idea is that political decisions should be grounded in public opinion, not only on electoral results and on the negotiations among elite actors.

From this perspective, data visualizations become significant as part of public discourse. Consider for instance how visualizations of carbon emissions data frequently are employed in public discussions about transport policy. Data visualizations may here function as support for an argument, or as arguments in their own right. As part of public deliberation, data visualizations contribute to the formation of public opinion about contested matters, to which decision- and policymakers ideally should be attentive. The public circulation of data visualizations may also inform decision-makers directly, and people's voting preferences. In addition to how voters make tactical decisions based on visualizations of parties' electoral performances, visualizations of the different parties' stances on key political issues-from climate to immigration policy_inform voters' party preferences.

However, the questions of who engages with data visualizations and where in the public sphere engagement occurs are important for their bearings on political decision-making. As such, the political theorist Nancy Fraser (1992) introduces a clarifying distinction between 'weak' and 'strong' publics. Weak publics, according to Fraser (1992, p. 134), are those publics 'whose deliberative practice consists exclusively of opinion formation and does not also encompass decision making'. Weak publics would typically include non-elite citizens and media audiences. Strong publics, by contrast, are those 'whose discourse encompasses both opinion formation and decision making' (p.134) and may include politicians and bureaucrats. Consequently, the direct impact of data visualizations on political decisions will be stronger when they engage strong publics. 
Further, the public sphere may facilitate interventions or 'watchdogging' where critical issues are brought into public attention by means of data visualizations. Whereas this is an institutional responsibility of journalism, Suman (this volume) illustrates how also actors from civil society (in her case Greenpeace) can spread visualizations of political interest (haze reports) in the public sphere, to ensure greater accountability in the government's handling of such problems and also to mobilize critical publics.

\section{Data visualizations and ideology}

The perspective of Data visualizations and ideology captures the ways in which data visualizations privilege certain views of the world, and through dissemination and audience engagement thus work as manifestations or carriers of ideology. From this perspective, data visualizations are integral to the production of meanings, signs, and values in social life, and, according to Marxian thought, a vehicle for the legitimation of the ideas of a particular group or class. Through their dissemination, data visualizations thus may work in the service of particular ideologies - be it for change or for preserving the status quo. Several chapters in this book highlight how data visualizations are not innocent or neutral representations of facts, but are indeed promoting a certain view of the world or establishing a certain kind of epistemology. Hill (this volume) for instance, shows how data visualizations of abortion work to naturalize limitations on access to reproductive healthcare.

From an ideological perspective, data visualizations primarily have pre-political significance, rather than direct bearings upon politics (understood in a narrow sense). Data visualizations can contribute to naturalize or challenge certain broad worldviews. Consider for instance how data visualizations can frame socio-economic disparities as dramatic and critical, or conversely, as natural and inevitable. Such worldviews promoted through data visualizations may in turn be highly significant in legitimating or challenging the priorities of political bodies or actors, or in informing voting preferences.

This perspective contrasts to that of deliberation. A deliberative perspective presupposes that data visualizations form part of the exchange of arguments open to validation or critique. In contrast, data visualizations seen from an ideological perspective, work to conceal or naturalise propositions that are nonetheless laden with a particular view of the world. 
David Beer (2016) presents a compelling example of how data visualizations do ideological work, or, more precisely, how the visualization of metrics naturalize and augment neoliberal ideology. Beer argues that the pervasiveness of metrics and their circulations produce certain kinds of knowledge ('regimes of truth'). Key to his argument is that the increasing pervasiveness of metrics in social and political life generates a kind of 'numerical thinking' in which (self-)measurement and competition are internalised as self-evident values. In turn, these values are contingent with the modus operandi of neoliberalism where competition and free markets sit at the core. Data visualization is thus a key vehicle for the promotion of numerical thinking. As Beer writes (2016, p. 114), 'How metrics look and how they are visualized can dictate their impact. In each case, these metrics have the capacity to create realities'. Whereas this dynamic does not impact directly on the workings of politics in a narrow sense, the advancements of metrics through visualizations can be seen to pave the way for neoliberal governance.

Beer's account, however, brings into attention an important distinction between data visualizations as ideology and data visualizations as carriers of ideology. Beer is exemplifying the former. For Beer, who is inspired by the discourse theory of Michel Foucault, data visualizations discursively constitute the trust in numbers that is at the heart of neoliberal ideology. In its forms and modes of production, data visualization here embodies the very logic of neoliberalism. In contrast, we can think of data visualization as a tool for symbolic representation of issues of ideological significance. From this latter perspective, ideology is not contained in the form of data visualizations themselves, but is a matter of what is represented and how. Consider for instance how visualizations of a country's socio-economic performance may highlight data indicating either commercial growth or the redistribution of resources. Whereas the former can be seen to promote a view of the world where market liberalism is natural and desirable, the latter could be seen to promote social democracy or socialism.

Either way, data visualizations may be used instrumentally by various actors to support or promote particular worldviews. In such scenarios, the public sphere can be seen as a 'battlefield' for conflicting or competing ideologies. A number of examples of how data visualizations can be used to challenge certain worldviews are contained within this book. One is offered by the contribution by Ricker, Kraak, and Engelhardt (this volume), calling for a feminist cartography. These scholars argue that the production and dissemination of maps attentive to gender issues and needs are important to challenge patriarchal ideology. 


\section{Data visualizations and citizenship}

Data visualizations and citizenship is a perspective emphasizing the different ways in which data visualization can enable people to function as citizens. It does not capture direct impacts of data visualizations on political processes or decision-making. Rather, the political significance here resides in how data visualization may foster engagement with these processes and political participation more broadly.

This perspective lends itself to participatory models of democracy, most notably what is known as the republican and deliberative models of democracy (Held, 2006). These posit that democratic citizenship is not confined to the act of voting, and that broad citizen participation and engagement constitute the core of democratic politics. It is important to note, though, that in the same way that data visualization works as a resource for informed and critical citizenship, it may also work as a tool for misinformation and manipulation, and consequently contribute to the erosion of informed and critical citizenship.

An obvious capacity through which data visualization may enable citizens is by providing them with information and with tools for making sense of complicated political issues. It may enable citizens to take part in political will and opinion formation as well as to form informed party preferences. Moreover, data visualizations may also provide valuable input to the everyday and informal discussions among 'ordinary people', sitting at the core of deliberative models of democracy.

Coleman and Moss's (2016) study of televised election debates and their audiences offers one example of how data visualization may work to promote informed and critical citizenship. In the context of television debates, they identify data visualization as a key sense-making technology through which viewers can be addressed in an inclusive manner by politicians, as well as a tool for citizens to understand and evaluate claims made by politicians and parties.

Moreover, given open data sources and rising levels of technical literacy, the production and dissemination of data visualizations by citizens or activists constitutes a bottom-up form of civic engagement in itself. Such a bottom-up perspective is highlighted by D'Ignazio \& Bhargava (this volume). These contributors argue that the diffusion of visual-numerical literacy is critical for enabling non-elite members of society to produce their own counterhegemonic data visualizations. Similarly, Pinney (this volume) highlights the importance of data literacy for participation in today's datafied society.

So far in my treatment of data visualizations' relevance for citizenship, I have highlighted what could roughly be labelled as 'cognitive' dimensions. However, people's engagement with political causes or issues, and 
inclination to participate more generally, is a question about more than rational judgements and uptake of factual information. It is also a matter of feelings and belongings. Civic engagement hinges on sympathies, antipathies, identifications, passions, and so on. In order to be motivated to act as a citizen, one needs to feel as part of the community that makes up the polity (Kymlicka, 2015; Dahlgren, 2002). Or conversely, feelings of being excluded from community may also motivate political engagement, or political struggle for inclusion more generally. These affective and affinitive aspects of citizenship imply a significant role for data visualizations.

For one, data visualization may spur emotional engagement around certain causes. As shown by Kennedy and Hill (2017), emotions are an integral part of the experiences people have when encountering different aspects of data visualizations, including the data themselves and the subject matter of the visualizations. This point is also made by Gutiérrez (this volume). In the critical context of how industrial countries exploit developing countries' natural resources, she highlights the potential of affective data visualization for mobilizing people to become political activists.

Moreover, data visualizations may play an important role in democratic inclusion. Democratic inclusiveness is not only a matter of who gets to speak or vote. It also concerns whether people feel they are represented in and part of a community or not. As argued by the political philosopher Charles Taylor (1994), the recognition — the positive affirmation—of people's presence is a key motivating force for participation in society. Elsewhere, I have also argued (2017) that media constantly mirror back images of their audiences, who in turn interpret and reflect upon these images. Media representations thus constitute an increasingly important source for recognition. Crucially, data visualizations also bring representations of identities and perspectives into the public sphere, which are engaged with by members of the public. As Kennedy and Hill point out:

Although more abstract than other visual forms, data visualizations act as media images as well as representations of data, and as such they have the potential to evoke empathy, pity, sorrow, shame and other emotions. (2017, p. 14)

Consequently, audiences may feel recognized, misrecognized, or not recognized at all by data visualizations (see Wihbey, Jackson, Cruz, \& Foucault Welles, this volume). Such visualization-enhanced recognition may in turn be important for people's sense of belonging to a community, and in turn their motivations for civic engagement. 
A very basic example is national weather forecasts. These visualizations involve a simple form of recognition: the acknowledgement of peripheral parts of a country and the people who live in them as part of the country. Another example is political maps. Political maps involve the recognition of sovereign territories as nation states, and the non-recognition of others-often those with unfulfilled claims to sovereignty. What is included and what is not in data visualizations - who is given visibility through data visualizations - thus emerges as a condition for recognition. This capacity of data visualizations to give visibility to groups or persons is addressed in this book in Alamalhodaei, Alberda, and Feigenbaum's chapter, which calls for more 'humanized ‘data visualizations. Similarly, Gray's chapter (this volume) highlights the narrative and affective capacities of data visualizations, which in turn may enable visibility and recognition of persons or groups.

Yet another example is visualizations of crime statistics and how these routinely present specific immigrant groups as perpetrators of crime. Seen from the perspective of persons belonging to these specific immigrant groups, these visualizations may form part of an overall negative media framing that, for them, is experienced as a misrecognition of their presence in society, and as being counted as a burden rather than a resource. As a source for (mis)recognition, data visualizations thus may contribute, positively or negatively, to people's sense of being accepted, and consequently, their motivation for civic participation.

\section{Data visualizations as political-administrative steering tool}

The perspective of Data visualizations as political-administrative steering tool captures scenarios where data visualization is used instrumentally to guide policy or decision-making. It is thus a perspective in which data visualization is assumed to have a strong and direct link to politics. In contrast to the other perspectives, the significance of data visualizations here does not necessarily depend on their circulation in the public sphere or their uptake by non-expert citizens. Rather, the perspective assumes a trajectory directly from experts to policymakers or between other elite actors, who are often connected to scientific, economic, and political institutions. I will illustrate this perspective using an example from the field of global climate policy. ${ }^{1}$

1 In researching this perspective, I consulted Eilif Ursin Reed who is a communication adviser at CICERO Center for International Climate Research, and to whom I am grateful for comments and advice. 
Here, I zoom in on how visualizations of climate data inform how The United Nations Framework Convention on Climate Change (UNFCCC) sets its climate policy goals. A main focus of this political body is to set the temperature target; the maximum allowable warming to avoid dangerous anthropogenic interference in the climate. The UNFCCC regularly commissions scientific reports on which to base policymaking. These reports are commissioned from The Intergovernmental Panel on Climate Change (IPCC), a scientific body consisting of thousands of scientist and other experts. As part of these lengthy reports the IPPC produces a short version of the report, called Summary for Policymakers, which addresses policymakers directly. Among other things, this summary presents research-based scenarios guiding policymakers, who also finally approve the summary. These summaries routinely contain data visualizations.

For instance, a regular staple in these summaries has been the visualization feature called the 'burning ember' (see New York Times, 2009). In the form of coloured bar graphs, the 'burning ember' visualizes risks (the redder, the more critical) associated with different scenarios of increased global mean temperatures. As such, the 'burning ember' provides an example of how data visualizations address 'strong' publics, whose discourse encompasses both opinion formation and decision-making. It is thus also an example of how data visualizations may attain very concrete and manifest political significance as aids for political decisions. However, the inclusion of the 'burning ember' has been criticized precisely for being too instructive. Rather than merely visualizing problems - which is the mandate of the scientists - it is criticized for employing visual rhetoric that command certain responses (see, for instance, Mahoney \& Hulme, 2012).

\section{Conclusion: Avenues for further research}

This chapter has outlined four important perspectives through which we can think of data visualizations as politically significant. Moreover, it has attempted to clarify the contexts where data visualizations become politically significant, and the notions of politics implied by these contexts. Each of these perspectives implies different avenues for research. In the following, I will briefly point to some of the most important of these.

The ways in which data visualizations form part of public deliberations actualizes questions about the argumentative and rhetorical nature of such visualizations. Do data visualizations, as they appear in public debate, work to clarify or conceal arguments? Do they lay themselves open to (in) 
validation? And how are rhetorical devices used to convince? Such questions are important to answer in order to attain a more critical understanding of how data visualizations contribute to public and political discourse- or more generally; to manipulative or argumentative public spheres.

Likewise, there is a need for empirical research into how data visualizations textually promote ideology, and how citizens' worldviews are shaped or negotiated in their encounters with data visualizations. A further step would be to explore empirically, and in more detail, how the ideological work done by data visualizations connects to or prepares the ground for political agendas.

Moreover, there is a need for a clearer understanding of how the expansion of data visualization affects people's ability to function as citizens. Through which capacities and in which contexts do data visualizations work as a resource for citizenship, and when do they not? In particular, the affective and affinitive dimensions of how people engage with data visualizations warrant further research. When and how do data visualizations engender feelings of being recognized among audiences, and how may such feelings contribute to audiences' civic affinities?

Lastly, there is need for more empirical research into when and how data visualizations are used instrumentally as an aid in political or administrative decision-making processes. Such endeavours would enable insight into some of the very concrete and manifest ways in which data visualization affects politics. This would require investigations into the specific contexts where decision-making takes place, be they political, administrative, or legal bodies.

Some of this much-needed research is underway, and can be found in the chapters in this book.

\section{References}

Beer, D. (2016). Metric power. York: Palgrave Macmillan.

Coleman, S., \& Moss, G. (2016). Rethinking election debates: What citizens are entitled to expect. The International Journal of Press/Politics, 21(1), 3-24. https:// doi.org/10.1177/1940161215609732

Couldry, N., \& Hepp, A. (2016). The mediated construction of reality. Cambridge: Polity Press.

Dahlgren, P. (2002). In search of the talkative public: Media, deliberative democracy and civic culture. Javnost: The Public, 9(3), 5-26.

Fraser, N. (1992). Rethinking the public sphere: A contribution to the critique of actually existing democracy. In: C. Calhoun (Ed.), Habermas and the public sphere. (pp. 109-43). Cambridge: MIT Press. 
Habermas, J. (1994). Three normative models of democracy. Constellations, 1(1), 1-10. https://doi.org/10.1111/j.1467-8675.1994.tboooo1.x

Habermas, J. (2006). Political communication in media society: Does democracy still enjoy an epistemic dimension? The impact of normative theory on empirical research. Communication Theory, 16(4), 411-426. https:// doi.org/10.1111/j.1468-2885.2006.00280.x

Held, D. (2006). Models of democracy (3rd ed.). Cambridge and Malden, MA: Polity Press.

Kennedy, H., \& Hill, R. L. (2017). The feeling of numbers: Emotions in everyday engagements with data and their visualisation. Sociology, 52(4), 830-848. https:// doi.org/10.1177/0038038516674675

Kennedy, H., Hill, R. L., Aiello, G., \& Allen, W. (2016). The work that visualisation conventions do. Information, Communication and Society, 19(6), 715-735. https:// doi.org/10.1080/1369118X.2016.1153126

Kymlicka, W. (2015). Solidarity in diverse societies: Beyond neoliberal multiculturalism and welfare chauvinism. Comparative Migration Studies, 3(17). https://doi. org/10.1186/s40878-015-0017-4

Mahoney, M., \& Hulme, M. (2012). The colour of risk: An exploration of the IPCC's 'Burning Embers' diagram. Spontaneous Generations: A Journal for the History and Philosophy of Science, 6(1), 75-89. https://doi.org/10.4245/sponge.v6i1.16075

Nærland, T. U. (2017). Altogether now? Symbolic recognition, musical media events and the forging of civic bonds among minority youth in Norway. European Journal of Cultural Studies. Advance online publication. https://doi. org/10.1177/1367549417719013

New York Times (2009) [Digital image]. Retrieved August 28, 2018 from https:// archive.nytimes.com/www.nytimes.com/imagepages/2009/02/23/science/ dotearth_large.html

Taylor, C. (1994). The politics of recognition. In: A. Gutmann, A. Appiah, \& C. Taylor (Eds.), Multiculturalism: Examining the politics of recognition. (pp. 25-73). Princeton, NJ: Princeton University Press.

van Dijk, J. (2014). Datafication, dataism and dataveillance: Big data between scientific paradigm and ideology. Surveillance \& Society, 12(2), 197-208. http:// doi.org/10.24908/ss.v12i2.4776

\section{About the author}

Torgeir Uberg Nærland is a researcher at the Department of Information Science and Media Studies at the University of Bergen. Focusing on textual, receptive, and institutional dimensions of expressive culture, his research explores the intersections between aesthetics and politics. 
